\title{
Competition and Price Discrimination in the Parking Garage Industry
}

\author{
By HAIZHEN LIN AND YIJIA WANG*
}

We study the relationship between competition and price discrimination through an empirical examination of hourly price schedules in the parking garage industry. We find that the degree of price schedule curvature decreases with competition, implying a greater proportionate drop in low-end prices than in high-end prices when competition intensifies. We provide an explanation for our findings using differences in search behaviors between shortand long-term customers.

Keywords: competition, price curvature, price discrimination, consumer search, parking garage industry

\section{Introduction}

Will increased competition enhance or diminish a firm's capability to price discriminate? The classic textbook treatment states that market power enables a firm to exercise price discrimination. However, existing literature, both empirical and theoretical, has delivered mixed findings regarding how competition affects the extent of price discrimination. ${ }^{1}$ We revisit this question

\footnotetext{
* Lin: Department of Business Economics and Public Policy, Kelley School of Business, Indiana University, Bloomington, IN 47401 Email: hzlin@indiana.edu; Wang: NERA Economic Consulting, Email: yijia.wang@nera.com. We would like to thank Dan Ackerberg, Mike Baye, Meghan Busse, Kris Gerardi, Ginger Jin, Alessandro Lizzeri, Nicola Persico, Jeffrey Prince, Marc Rysman, Adam Shapiro, Joel Waldfogel and Jidong Zhou for their helpful discussions. We would also like to thank Alex and Ben Sann at Bestparking.com for making the data available to us. Comments and suggestions from the participants at the $7^{\text {th }}$ International Industrial Organization Conference and the 2011 Asian Meeting of the Econometric Society were appreciated. All errors are our own.

${ }^{1}$ See, for example, Stole (1995), Stavins (2001), Rochet and Stole (2002), and Borzekowski, Thomadsen and Taragin (2009).
} 
through an empirical examination of hourly parking price schedules (i.e., parking prices ranging from 1 to 12 hours) in the parking garage industry.

The parking garage industry proves an interesting setting to examine the relationship between competition and price discrimination. First, parking prices usually vary nonlinearly with the length of parking hours. The marginal costs of providing an additional hour of parking are likely constant. This is true whether the capacity constraints of parking garages are binding or not. ${ }^{2}$ As a result, nonlinearity in observed prices could be attributed to price discrimination. ${ }^{3}$ Second, consumer search behaviors play a crucial role in determining equilibrium prices in the parking garage industry where firm heterogeneity is largely geographical. Increased competition lowers search costs due to shortened travel distances between garages, which could have a disproportionate effect on the search behavior of short-term parking customers compared to long-term customers, leading to a change in the curvature of price schedules. ${ }^{4}$ Finally, the feature of constant marginal costs in this industry conveniently allows us to draw a direct inference regarding the relationship between competition and price discrimination by examining the curvature of price schedules, whereas such a conclusion is difficult to draw in other studies due to a lack of reliable data on costs.

We first investigate how the intensity of competition affects hourly parking prices. Using a cross-sectional dataset of parking garages in Manhattan, New York in 2004, we find that competition drives down overall price levels. ${ }^{5}$ We then

\footnotetext{
${ }^{2}$ When capacity constraints are binding, the tradeoff for selling an additional hour of parking is to forgo the spot for a potential 1-hour customer. When capacity constraints are not binding, the marginal costs of each additional hour of parking are zero across different durations. See more detailed discussion in Section 5.

${ }^{3}$ We expect almost no substitution between drastically different parking durations (e.g. between 2 and 8 hours of parking) when compared to the usual amount of substitution between the top and bottom of a nonlinear price schedule; the parking industry sees a combination of second- and third-degree price discrimination. See more detailed discussion in Section 5.

${ }^{4}$ We only examine price schedules of hourly parking. Weekly and monthly parking are not within the scope of our investigation. In this paper, long-term parking refers to parking of longer hours relative to short-term parking which refers to parking of shorter hours.

${ }^{5}$ We define a market as encompassing the area within a radius of 0.5 miles from the center garage, or an alternative radius of 0.3 miles. We construct a measure of competition using the Herfindahl-Hirschman index, calculated using the fraction of
} 
examine how increased competition alters the curvature of a parking garage's hourly price schedule. Following the identification strategy established by Busse and Rysman (2005), we find that price schedules become less curved as competition intensifies, indicating that prices of short-term parking drop proportionally more than those of long-term parking. Our findings are robust to alternative competition measures, alternative sample selection methods and alternative functional forms regarding the relationship between competition and price curvature. Given that the marginal costs of an additional hour of parking are likely constant, our findings imply that increased competition leads to less variation in the price-cost margin and therefore less price discrimination in the parking garage industry. ${ }^{6}$

We provide an explanation for our findings using differences in search behaviors between customers of short- and long-term parking. Long-term customers search more intensely than short-term customers, as their gain from searching is more significant and more likely to be repetitive. When competition intensifies with the entry of new garages into a market, search costs are reduced due to shortened travel distances between garages. As a result, short-term customers increase their search intensity, leading to an increase in the fraction of informed customers, and a consequent decrease in overall short-term parking prices. ${ }^{7}$ Long-term customers also increase their search intensity as a result of an increased number of options. However, long-term customers are less affected by increased competition, as a larger proportion of them are already informed about the existing price distribution prior to the increase in competition. The fact that short-term customers respond more to changes in competition leads to a larger competition effect on the prices of short-term parking than on long-term parking.

garages owned by each company in a market. We also use other measures of competition for robustness purpose.

${ }^{6}$ Both price-cost markup and price-cost margin have been used to define price discrimination in the literature. See Clerides (2004) for a comprehensive discussion and comparison of these two definitions. In this paper, both definitions lead to the same conclusions, so we focus our discussion using the price-cost margin.

${ }^{7}$ See, for example, Varian (1980), Wilde and Schwartz (1979), Salop and Stiglitz (1977) and Stahl (1989). 
We present some evidence to support this search explanation.

Our paper is closely related to the study by Busse and Rysman (2005), which examines price nonlinearity in the Yellow Page advertising market. However, while our study is able to interpret the relationship between price discrimination and competition, such an inference is difficult to draw in the study of Busse and Rysman (2005) due to a lack of cost information. ${ }^{8}$ Busse and Rysman's findings differ in that they find competition drives down prices more for large ads than for small ads. We provide several explanations to reconcile this result disparity.

Our paper contributes to the literature on price discrimination and price dispersion by examining the role of competition. The existing theoretical literature yields mixed predictions about how competition affects a firm's incentive to price discriminate (e.g., Stole, 1995; Armstrong and Vickers, 2001; Rochet and Stole, 2002). The ambiguity in theoretical predictions has inspired a growing body of empirical literature. ${ }^{9}$ In a recent study, Gerardi and Shapiro (2009) study airline ticket prices and find that competition has a larger negative effect on the top portion of the price distribution than on the lower portion, especially on routes with customers characterized by relatively heterogeneous elasticity of demand. Seim and Viard (2011) study how market entry of competitors affects nonlinear pricing strategies (i.e., the number of different pricing plans offered) in the U.S. cellular telecommunications market. They find that additional competition leads to increased plan variety and causes prices to drop more for high-valuation consumers. Dai, Liu and Serfes (2012) find a nonmonotonic relationship between competition and price dispersion in airline ticket

\footnotetext{
${ }^{8}$ Whether competition increases or decreases price discrimination in the Yellow Page advertising market depends on the relative costs of offering large versus small ads.

${ }^{9}$ For example, Borenstein (1991) examines price discrimination in the competitive retail gasoline market and finds that a decrease in the number of gasoline stations offering leaded gas leads to an increase in the margins of leaded gas, relative to the margins of unleaded gas. Verboven (1999) finds a price premium for optional engine power in car segments. Borenstein and Rose (1994) and Stavins (2001) both look at the relationship between competition and pricing in the airline industry. Borzekowski, Thomadsen and Taragin (2009) examine second- and third- degree price discrimination in the mailing lists market. Also, see Cohen (2008) for a structural analysis of price discrimination in the paper towel market and an excellent review of other structural studies in the literature.
} 
prices. Our study provides unique insights from the parking garage industry, which has not been addressed in other works.

Additionally, our paper contributes to existing literature on consumer search behavior and equilibrium pricing. ${ }^{10}$ Existing search literature typically assumes fixed search costs, which may contribute to the positive relationship between competition and equilibrium prices (e.g., Satterthwaite, 1979; Rosenthal, 1980; Varian, 1980; Stiglitz, 1987; Stahl, 1989, 1996; Schulz and Stahl, 1996; Janssen and Moraga-González, 2004). Our findings highlight the importance of allowing search costs to vary with the number of competitors in a relevant market. ${ }^{11}$ If a less concentrated market is associated with lower search costs, enhanced competition would lead to a higher proportion of informed customers (or a greater intensity of search), as compared to predictions from models that assume fixed search costs. An increase in informed customers would strengthen the businessstealing effect, inducing firms to attach more importance to attracting these customers. As a result, enhanced competition might lead to lower prices, if the business-stealing effect dominates the surplus-appropriation effect.

The remainder of the paper is organized as follows: Section 2 describes the data and explains how we measure the intensity of competition; Section 3 examines the relationship between price and competition; Section 4 studies how price curvature responds to changes in competition and presents robustness tests; Section 5 discusses our findings and provides a search explanation; Section 6 concludes.

\section{Data}

\subsection{Data Source}

Our primary data set contains detailed information about locations, price

${ }^{10}$ See Baye, Morgan and Scholten (2006) for a review of the literature.

${ }^{11}$ Lach and Moraga-González (2012) present an oligopoly model where consumers differ in available price information. Utilizing different assumptions about how a change in the number of firms affects the information of the consumers, they find different results in terms of how increased competition affects the price distribution. 
schedules, and attributes such as ownership, for over 800 parking garages in Manhattan, New York in 2004. ${ }^{12}$ The data set accounts for more than $80 \%$ of all the parking garages in Manhattan at that time. ${ }^{13}$ Figure 1 provides a map of the garage locations covered in the data.

We used ArcMap (a Geographic Information Systems software) to geocode the address of each parking garage. Based on the geocoded coordinates and area boundaries, we assigned a neighborhood, census tract, tax block and tax lot to each garage in the data. The neighborhood boundaries were obtained from the Community Studies of New York, Inc. The census tract boundaries and demographics were taken from the U.S. Census Bureau, and the tax blocks, tax lot boundaries and other attributes came from MapPluto, complied by the New York City Department of City Planning. ${ }^{14}$ We associated each garage with the attributes and demographics of the area in which a garage is located.

\subsection{Price Menu}

Garages usually provide a number of rate options. Our data observes that a typical garage posts 5 different rates, with $90 \%$ of the garages offering between 3 and 8 rates. ${ }^{15}$ These rates generally fall into one of the following four categories: basic, overnight, maximum, and special rates. The basic rates specify prices for parking up to a given duration (l hour, 2 hours, 12 hours, etc.). In addition to basic rates, approximately $90 \%$ of the garages have an "overnight from" rate, which specifies a price for parking beyond a specific time, but with a total parking duration of less than 24 hours. ${ }^{16}$ This “overnight from” rate overrides basic rates when applicable. About a

\footnotetext{
${ }^{12}$ It is a cross-sectional data set compiled by the founders of the website www.bestparking.com.

${ }^{13}$ Our data coverage is not complete for the following areas: the Financial District, Chinatown, Lower East Side and East Village. In addition, areas above West and East 100th street are not included in our data. We will discuss sample selection in Section 2.4.

${ }_{14}^{14}$ The tax blocks and tax lot boundaries are used to identify land value and zoning characterizations for each garage.

${ }^{15}$ See an example in the appendix in which a garage lists 7 rates.

${ }^{16}$ A few garages offer an "overnight to" rate, which specifies a price for parking up to a particular time, after which the meter restarts.
} 
quarter of garages in the data also offer a maximum rate for not parking past the posted closing time. ${ }^{17}$ In addition, nearly $60 \%$ of the garages offer at least one daily special rate. A common example of a daily special rate is the "early bird special," a discounted price for customers who enter a garage during a specific time window, leave before a particular time, and stay less than a given number of hours. Special rates imply that parking prices depend not only on how long a person parks, but also on when that person enters a garage. ${ }^{18}$

There also exists heterogeneity in different groups of customers and the availability of outside options based on the entering time. Parking garages could offer price menus based on entering times to target different groups of customers. It is a reasonable assumption that customers who park early in the morning to get to work have different preferences than those parking at night to go out to dinner. They may differ in relative valuations of various parking durations (i.e., customers who park to get to work would value 8-hour parking much more than 2hour parking; however, customers who park to go out to dinner might prefer 2-hour parking). ${ }^{19}$ Moreover, outside options vary with different entering times. At night, street parking that is not available during daytime hours becomes available, which could change a customer's willingness to pay for garage parking.

Given the above characteristics, it is important to study price menus for a given entering time in order to compare prices across garages. Our

\footnotetext{
${ }^{17}$ Sometimes, a garage posts a closing time just to specify the time when the "overnight from" rate becomes applicable. In such a case, the garage could be open 24 hours.

${ }^{18}$ Here is a simple example to illustrate how prices could depend on when a customer enters the garage. Assume that a customer parks her car for 8 hours in a garage that opens at 6 a.m. and closes at 12 a.m. This garage has a l-hour, a 2-hour, a 10-hour, an "overnight from 12 a.m." rate and an "early bird special" rate. If she enters the garage during the "early bird special" hours, then she pays the "early bird special" rate. If she enters during the non-"early bird special" hours and leaves before midnight, she pays the 10-hour rate. If she enters the garage at 10 p.m. and leaves at 6 a.m. the next morning, she has to pay the "overnight" rate.

${ }^{19}$ For people who go out to dinner, 8-hour parking is likely too long, which generates inconvenience and disutility.
} 
study focuses on price menus for the entering time of 12 p.m., when very few garages (7.8\%) offer daily special rates, and 8 a.m., when the proportion of garages that offer special rates is the highest $(54.4 \%) .{ }^{20}$ We construct a 1 - to 24 hour price schedule utilizing the posted rates for each garage, with the detailed method of construction covered in the appendix. ${ }^{21}$

Summary statistics of hourly parking prices are presented in Table 1A. The average price is $\$ 12.67$ for 1 -hour parking and $\$ 25.34$ for 12 hour parking. Overall, parking prices increase non-linearly with durations, with more discounts for longer durations.

\subsection{Relevant Market and Competition Measures}

We assume that people only travel within a certain distance from their preferred location for parking services. Garages in the Upper East Side generally do not compete with those in the East Village. To this end, we restrict the competition for a particular garage to garages located within a given radius from the center garage. Garages within this radius are considered to be in the same market as the center garage, and are referred to as the "relevant competing garages." ${ }^{22}$ We use radii of 0.3 and 0.5 miles to identify markets. In Manhattan, 0.5 miles is approximately the distance of 10 blocks. ${ }^{23}$ The radius of 0.3 miles is used for robustness purposes.

A majority of the garages in our data are owned and operated by a small group of companies. For example, the two biggest companies (ICON and

\footnotetext{
${ }^{20}$ We also focus our analysis on Monday price menus. Price menus for a given entering time exhibit little variation across weekdays, and the variation between weekdays and weekends is also minimal.

${ }^{21}$ We focus our analysis on the 1- to 12-hour duration. A third of the garages in our sample do not operate 24 hours, which implies that, if we examine a price schedule on a 24-hour basis, prices for some duration will be missing. For a simple illustration, assume a customer parks her car at 2 p.m. in a garage that operates from 6 a.m. to midnight. Parking for 12 hours is not available because the garage is closed after midnight and she cannot pick up her car at 2 am. However, she can park for 16 hours and retrieve her car when the garage reopens. In this example, prices for parking for 10 to 16 hours would be missing.

${ }^{22}$ Some studies on entry and market concentration, such as Bresnahan and Reiss (1991), require markets to be completely isolated so competition only comes from within a market and is not affected by firms in other markets.

${ }^{23}$ It normally takes about 10 to 15 minutes to walk across 10 blocks in Manhattan. In our analysis, the distance between garages is a straight-line distance. Given that one has to walk along streets or avenues to travel between two points, the walking distance between the garages is usually greater than the distance measure calculated in our analysis.
} 
CENTRAL) operate more than $35 \%$ of the garages in the sample. The four biggest companies (ICON, CENTRAL, GMC and IMPERIAL) own about 50\% of the garages and the six biggest companies own about $60 \%$ of the garages in the data set. For the remaining garages, about $15 \%$ are operated by another 20 companies that own multiple garages, while the other $25 \%$ are operated by individual companies that own one parking garage each.

We measure competition using the negative value of the HerfindahlHirschman index (the "HHI"), calculated by summing the squared fraction of garages owned by each company in a market. ${ }^{24}$ The negative value of the HHI is utilized, because competition is generally negatively associated with market concentration. Several alternative measures of competition are used for robustness purpose. One measure calculates HHI using the fraction of parking spots (i.e. capacity) owned by each company in a market. Another measure uses the number of competing companies in a market. The last measure uses the number of parking garages in a market. The HHI derived from the fraction of garages by company is our preferred measure of competition, because it is more closely related to firms' pricing behaviors than other competition measures. For example, markets with the same number of garages could have different levels of market concentration, depending on the ownership structure of individual garages. In such cases, we should expect different pricing behaviors across these markets with the same number of garages. Similarly, a simple count measure of companies ignores differentials in market dominance across companies. As a result, the HHI provides a more relevant competition measure for our analysis. Our results are robust to the alternative competition measures, discussed in Section 4.4.

Summary statistics for various competition measures are reported in Table 1A. Note that we calculate the HHI by summing the squared fraction of garages

\footnotetext{
${ }^{24}$ The HHI has been used in previous studies examining price and price discrimination such as Borenstein and Rose (1994) and Gerardi and Shapiro (2009).
} 
owned by each company; therefore, a value of 1 denotes a monopoly firm. A market defined by a 0.5-mile radius, has an average HHI of about 0.11 with a standard deviation of 0.04 . The HHI is larger if we use the alternative radius of 0.3 miles. The HHI-by-capacity provides a consistent measure of competition, with the median of about 0.13 for markets defined by a radius of 0.5 miles. In our data, the median numbers of competing companies within the radii of 0.3 and 0.5 miles are 16 and 30, respectively. ${ }^{25}$ The median numbers of competing garages within a radius of 0.3 and 0.5 miles are 33 and 83, respectively. The four firm concentration ratio based on the fraction of garages owned by companies in a market ranges from 0.38 to 0.75 , with the median being $0.55 .{ }^{26}$ We also report the fraction of garages owned by the same company as the center garage as a measure for the center garage's market power. We include this as an additional explanatory variable, so our estimation measures how a change in market competition affects prices for the center garage, after controlling for the center garage's market power. ${ }^{27}$

\subsection{Sample Selection and Market Characteristics}

Our data set covers more than $80 \%$ of the garages in Manhattan. Since our data set does not cover the areas above West and East 100th street, the competition measures calculated for garages that are close to 100th street were inaccurate. For this reason, we exclude all garages north of 95th street from our final analysis. Moreover, our data is not complete in certain areas (e.g., the financial district and Chinatown). For the same reason, we exclude garages close to the boundaries in those areas using garage location information. ${ }^{28}$ Our final

\footnotetext{
${ }^{25}$ About $40 \%$ of the garages are owned by small or individual companies, explaining the existence of a relatively large number of competing companies in the data.

${ }^{26}$ The four firm concentration ratio provides another competition measure. The estimation results are similar so not reported and discussed in the paper.

${ }^{27}$ Our results do not significantly change when we exclude the measure of the center garage's market power from our estimation.

${ }^{28}$ The area south of $20^{\text {th }}$ Street is incomplete in regard to the garage data. Therefore, we exclude the garages south of $25^{\text {th }}$ Street out of concerns that their competition measures might not be accurate.
} 
sample consists of garages to the south of 95th street and north of 25th street. We also conduct a robustness test using an alternative sampling method, with the details covered in Section 4.4.

Table $1 \mathrm{~B}$ provides summary statistics for the areas in which a garage is located. About 59\% of the garages are located in a commercial district, about $34 \%$ in a residential district, and the remaining are located in a manufacturing district. The average land value is $\$ 281$ per square feet. The median income of the census tract is about $\$ 72,000$, and the average population size is about 6,000 .

\section{Price Level and Competition}

In order to establish a valid relationship between price and competition, one has to control for demand and costs shifters, observed and unobserved, that affect both price and competition. The level of competition is not predetermined; firms decide to enter and exit a market based on their conduct and performance, including prices. This feedback behavior, based on the aforementioned characteristics in relation to market structure, implies that any factor affecting prices may be correlated with the level of competition. ${ }^{29}$ In the analysis below, we use the census tract fixed effects to control for unobserved heterogeneity at the census tract level. ${ }^{30}$

The empirical model examining the relationship between price level and competition is specified as follows:

$$
\begin{aligned}
& \ln \left(p_{i}\right)=\beta_{0}+\beta_{1} \operatorname{comp}_{i}+\beta_{2} \ln (\text { landvalue })+\beta_{3} \text { income } \\
& +\beta_{4} \text { population }+\beta_{5} \text { prop_owncomp }+\beta_{6} Z_{M}+\beta_{7} Z_{R} \\
& +\beta_{8} D+\beta_{9} Z_{R} D+\operatorname{Track}_{k}+\varepsilon_{i}
\end{aligned}
$$

where $p$ is the parking price for a given duration, comp is the competition

\footnotetext{
${ }^{29}$ See Evans, Froeb and Werden (1993) for a discussion on additional sources of endogeneity for market structure.

${ }^{30}$ The average size of a census tract in Manhattan is 0.07 square miles. The number of garages in a census tract ranges from 1 to 21 in the data, with a median of 5 .
} 
measure, landvalue is the value of the land per square feet, income is the median family income in the census tract where a garage is located and population is the census tract population. The variable prop_owncomp is the fraction of parking garages owned by the center garage's company in a market. $Z_{M}$ and $Z_{R}$ are the zoning dummy variables for manufacturing and residential districts, respectively. ${ }^{31} D$ denotes the zoning density, which captures the permitted bulk and land-use intensities; ${ }^{32} \operatorname{Track}_{k}$ is the census tract fixed effects. As density values vary with different zoning districts, ${ }^{33}$ we also include an interaction of zoning density and the residential district dummy in our analysis.

Our main competition measure is the negative value of the HHI based on the fraction of garages owned by each company in a market. Several factors can lead to an increase in competition. For example, entry of a new parking company enhances competition. Competition can also be intensified if the existing small companies (those that own a small fraction of the garages) open up more garages in the market. We use the negative value of the HHI in the estimation, so a negative coefficient for competition implies lower prices in more competitive markets. We also take the natural logarithm of prices for an easy interpretation of our results.

Table 2 reports the estimation results; the dependent variable is the natural logarithm of 1 -hour price when the entering time is 12 p.m. ${ }^{34}$ Results in columns 1 and 2 (without the census tract fixed effects) differ

\footnotetext{
${ }^{31}$ The commercial district is omitted in the regression.

${ }^{32}$ For a detailed description of the zoning density for various zones, please refer to the New York City Department of City Planning (http://www.nyc.gov/html/dcp/html/zone/zonehis2.shtml, accessed October 09, 2012).

${ }^{33}$ For a commercial district, zoning density ranges from 1 to 6 , where $D=1$ or 2 refers to areas with small retail and service shops, and $D=5$ or 6 refers to central business districts, such as Midtown and lower Manhattan. For a residential district, zoning density of 1-5 are low-density areas, and 6-10 refer to moderate- and high-density areas. Manufacturing districts do not have a density measure.

${ }^{34}$ The estimation was also performed for 2-hour to 12-hour prices for an entering time of $12 \mathrm{p}$.m. Additional analysis was conducted for an entering time of $8 \mathrm{a} . \mathrm{m}$. All results are similar to the results of 1-hour prices, and are not reported in the paper.
} 
largely from those in columns 3 and 4 (with the census tract fixed effects). If favorable demand factors that lead to high prices also attract more garages to enter a market, ignoring these factors might lead to an upward bias in the estimation of the coefficient for competition. The inclusion of the census tract fixed effects helps address such an endogeneity issue. Note that income and population vary at the census tract level, so their effect on price levels could not be identified when the census tract fixed effects are included in the model.

We focus on the 0.5-mile competing range in our result discussion. We find increased competition significantly drives down prices. If the HHI decreases by 4 percentage points (about one standard deviation in the data), holding everything else equal, the 1-hour parking price will drop by $12 \%$ on average. The coefficient on the land value, which controls for the cost of operating a garage, is neither statistically nor economically significant after we control for the census tract fixed effects, possibly because the census tract fixed effects have absorbed most of the variation in the land value.

The coefficient for prop_owncomp indicates that the larger the fraction of garages owned by the center garage's company in a market, the higher the prices that the center garage could charge. There is no significant difference in prices charged by garages located in commercial versus residential districts. However, prices are higher in manufacturing districts. Prices in the highest-density commercial districts (with a density measure of 6 ) are $12 \%$ higher than those in the lowest-density areas (with a density of 1).

Although the fixed effects approach is adopted to control for unobserved heterogeneity that might confound the relationship between price and competition, the endogeneity problem might remain. Here is a 
simple illustration. Assume that Garages A and B are located in the same census tract, but Garage $\mathrm{A}$ is close to a city landmark which is in another census tract. Garage A charges higher prices than Garage B because of a large volume of tourism and a high demand for parking. Meanwhile, Garage A faces more competition because the existence of the landmark attracts more garages to operate in the area. The census tract that contains the landmark causes the co-movement of competition and prices for Garage A. Our empirical model controls for unobserved heterogeneity only at the census tract level in which a garage is located. The co-movement discussed in the above example could not be fully controlled for with the inclusion of the census tract fixed effects. Therefore, additional caution needs to be taken in interpreting our estimation results.

Since many previous studies report a toward-zero bias due to the endogeneity of market structure (e.g. Manuszak and Moul, 2008; Mazzeo, 2002a), the magnitude of the competition effect in our model might be underestimated. In this study, we do not use the exact magnitude of the negative effect of competition to draw conclusions about the relationship between price curvature and competition. Instead, a general conclusion that competition drives down prices will suffice for our purpose. In this regard, an underestimation, if any, will not contaminate our investigation of price curvature, which is the focus of our study.

\section{Price Curvature and Competition}

In this section, we first discuss how we relate nonlinearity in hourly price schedules to price discrimination. Next, we examine the distribution of price curvature across garages in the data. We then study the relationship 
between price curvature and competition. Finally, we present results on robustness tests.

\subsection{Parking Price Schedules and Price Discrimination}

As discussed above, parking prices increase nonlinearly with parking durations, exhibiting discounts at the long end. What underlies the nonlinearity in parking price schedules is likely a combination of secondand third-degree price discrimination. On the one hand, parking prices of durations in close proximity exhibit second-degree price discrimination. For example, people parking near a restaurant to dine self-select into a 2- or 3-hour parking option based on their valuation of the incremental parking hour. On the other hand, parking of distant durations appears to serve distinct groups of customers. It is unlikely that people who park to go to dinner would consider 8-hour parking favorable, whereas commuters who park for work would not choose 2- or 3-hour short-term parking. Parking durations, if considerably different, automatically divide customers into different segments. Price discrimination to easily identified customer groups is third-degree price discrimination. In light of the discussion above, the curvature of parking price schedules seems to exhibit both second- and third-degree price discrimination.

\subsection{The Distribution of Price Curvature}

We follow Busse and Rysman (2005) and assume that a price schedule takes the following functional form:

$$
p_{i t}=v_{i} h_{t}^{\gamma_{i}}
$$

where $p_{i t}$ is the price for $t$-hour parking at garage $i, v_{i}$ is a garagespecific component that determines prices, $h_{t}$ is the parking duration, and $\gamma_{i}$ is the garage-specific curvature parameter. Price schedules exhibit discounts for long durations if $\gamma_{i}$ is smaller than 1 . The smaller the 
curvature parameter, the more curved the price schedule. ${ }^{35}$ In order to avoid confusion, we refer to the degree of curvature by how curved a price schedule is throughout the paper. Thus, a small curvature parameter $\gamma_{i}$ presents a large degree of curvature for a price schedule.

We first examine the distribution of $\gamma_{i}$ across garages in the data. We take the logarithm of equation (2) and estimate the following equation for each garage:

$$
\ln \left(p_{i t}\right)=\alpha_{i}+\gamma_{i} \ln \left(h_{t}\right)+\varepsilon_{i t}
$$

where $\alpha_{i}=\ln \left(v_{i}\right)$, and $\varepsilon_{i t}$ are independent and identically distributed (i.i.d.) across hours with a garage-specific variance $\sigma_{i}^{2}$. Table 3 reports the distribution of $\gamma_{i}$ for entering time being 12 p.m. and 8 a.m., respectively. In either case, we see significant discounts for long-term parking. The mean of the curvature parameter is 0.246 if the entering time is 12 p.m. and 0.171 if the entering time is 8 a.m. The maximum value of the coefficient $\gamma_{i}$ is smaller than 1, implying all garages practice some degree of discounts for longer parking durations. ${ }^{36}$

Price schedules have a larger degree of curvature (i.e., a smaller curvature parameter) for the entering time of 8 a.m. compared to 12 p.m. This may be because many garages impose a daily special rate for customers entering at $8 \mathrm{a}$.m. that is applied to most hours within the 1-to12-hour duration. This daily special rate represents a bigger discount at the high end of a parking price schedule, which leads to a greater degree of curvature.

\subsection{The Relationship between Price Curvature and Competition}

To examine the relationship between competition and price curvature,

\footnotetext{
${ }^{35}$ When the curvature parameter is 1 , the price schedule is a straight line. When the curvature parameter is smaller than 1 , the schedule becomes curved and exhibits discounts at the high end of parking durations.

${ }^{36}$ More than $99 \%$ of the estimated curvature parameters significantly differ from 1 for both entering times.
} 
we use the following specification,

$$
\gamma_{\mathrm{i}}=\delta_{0}+\delta_{1} \operatorname{comp}_{i}+\eta_{\mathrm{i}}
$$

where $\eta_{i}$ is an i.i.d. error with variance $\sigma_{\eta}^{2} \cdot{ }^{37}$ We are particularly interested in the sign and magnitude of the coefficient $\delta_{1}$. One way to proceed is to first estimate Equation (3) and then estimate Equation (4), but the standard errors of the estimates need to be adjusted for the second step because the dependent variable $\gamma_{\mathrm{i}}$ is estimated from the first step. Another way to proceed requires a researcher to substitute Equation (4) into Equation (3) and directly estimate $\delta_{1}$, as implemented by Busse and Rysman (2005). We follow the second method and estimate the following,

$$
\ln \left(p_{i t}\right)=\alpha_{i}+\delta_{0} \ln \left(h_{t}\right)+\delta_{1} \operatorname{comp}_{i} \ln \left(h_{t}\right)+\eta_{\mathrm{i}} \ln \left(h_{t}\right)+\varepsilon_{i t}
$$

where $\alpha_{i}$ is the garage fixed effects. Errors $\eta_{i}$ and $\varepsilon_{i t}$ are assumed independent; the sum of $\eta_{\mathrm{i}} \ln \left(h_{t}\right)$ and $\varepsilon_{i t}$ is the composite error term for the regression. Note that the composite error terms are not homoscedastic due to the presence of $\eta_{\mathrm{i}} \ln \left(h_{t}\right)$ and the assumption that variance $\sigma_{i}^{2}$ is garagespecific. The standard errors are estimated clustering at the garage level. ${ }^{38}$ Table 4 reports the regression results of Equation (5) for a 12 p.m. garage entering time. ${ }^{39}$ We focus our discussion on the parameter $\delta_{1}$ (the coefficient for $o m p_{i} \ln \left(h_{t}\right)$ ), which measures how competition affects price curvature. Columns 1 and 2 report the results without controlling for

\footnotetext{
${ }^{37}$ An alternative specification for Equation (4) adds all controls specified in Equation (1), such as land value and the census tract fixed effects. The results are similar and will be reported in Section 4.4.

${ }^{38}$ Equation (5) not only has heteroskedasticity, but also exhibits autocorrelation for the prices of the same garage because $\operatorname{cov}\left(\ln \left(\mathrm{p}_{\mathrm{it}}\right), \ln \left(\mathrm{p}_{\mathrm{ik}}\right)\right)=\sigma_{\eta}^{2} \ln \left(\mathrm{h}_{\mathrm{t}}\right) \ln \left(\mathrm{h}_{\mathrm{k}}\right)$. However, when we constructed the covariance matrix using $\widehat{\sigma}_{\eta}^{2} \ln ^{2}\left(\mathrm{~h}_{\mathrm{t}}\right)+$ $\widehat{\sigma}_{i}^{2}$ as the diagonal elements and $\widehat{\sigma}_{\eta}^{2} \ln \left(h_{t}\right) \ln \left(h_{k}\right)$ as the off-diagonal elements for the same garage and zero elsewhere, the matrix was not invertible and a feasible GLS could not be completed. We report the estimation results by clustering at the garage level. We also estimate Equation (5) using weighted least squares. The weights, $\widehat{\sigma}_{\eta}^{2} * \ln ^{2}\left(\mathrm{~h}_{\mathrm{t}}\right)+\widehat{\sigma}_{\mathrm{i}}^{2}$, are obtained as follows: first estimate Equation (3) and get $\widehat{\sigma}_{i}^{2}$, the estimated variance of $\varepsilon_{i t}$; then, use the estimate $\hat{\gamma}_{i}$ to run Equation (4) to get the estimated variance of $\eta_{\mathrm{i}}, \widehat{\sigma}_{\eta}^{2}$. The results are similar to the main findings in the paper.

${ }^{39}$ The results using prices of an 8 a.m. entering time are similar.
} 
garage fixed effects for the relevant competing radii of 0.3 and 0.5 miles, respectively. The results imply a nonsignificant association between competition and price curvature. However, if we control for the garage fixed effects, as shown in columns 3 and 4 of Table 4 , we find increased competition leads to a greater curvature parameter (or a less curved price schedule), and the effect is statistically significant.

Results when using the garage fixed effects specification can be interpreted as follows for the 0.5-mile relevant radius; on average, a garage's 12-hour price is 1.92 times its 1-hour price; if the HHI decreases by 4 percentage points (about one standard deviation in the data), the ratio of a 12-hour price to 1-hour price increases to 2.06 (or a $7 \%$ increase). Our results indicate that competition is inversely related to the degree of price curvature in the parking garage industry. ${ }^{40}$

\subsection{Robustness Tests}

\section{a. Competition Measure}

In addition to the HHI adopted in the main analysis, several alternative measures of competition are used for robustness purpose. The estimation results for the price equation (Equation (1)) are presented in Panel A of Table 5, and results for the curvature equation (Equation (5)) are reported in Panel B. The competition measure used in column 1 is the negative value of the HHI calculated as the summation of the squared fraction of parking capacities owned by each company in a market. Column 2 uses the log of the number of parking companies, and column 3 uses the $\log$ of the number of parking garages in a market. ${ }^{41}$ All results

\footnotetext{
${ }^{40}$ We also extend our analysis to price schedules up to 24 hours, and find qualitatively similar results.

${ }^{41}$ In a previous version of this paper, we also used a competition measure that controlled for differences in garage capacities (garages with large capacities would impose a higher competition pressure) and distance between garages (garages located one block away should be considered closer competitors than those located ten blocks away). Specifically, we calculated the level of competition for a given garage by summing up the number of parking spots of each relevant competing garage, weighted by an inverse function of the distance from the center garage to each competing garage. We also found a positive relationship between competition and curvature parameter if we used this competition measure.
} 
are consistent with our main findings. For the price level equation, we find that prices are negatively associated with competition after controlling for the census tract fixed effects. For the curvature equation, we find that increased competition leads to a greater curvature parameter, indicating a less curved price schedule.

\section{b. Sample Selection}

Our data does not cover all the parking garages in Manhattan in 2004. In order to ensure our competition measure is accurate and reliable, we restrict our main analysis to the areas south of 95th street and north of 25th street. As a robustness test, we further restrict our sample to garages located south of 90th street and north of 30th street. The results are reported in column 4 of Table 5, and are similar to our main findings discussed in the paper.

\section{c. Functional Forms}

We adopt a log-linear specification in order to examine the relationship between competition and price curvature (Equation (5)). To check whether our results are robust to other functional forms, we conduct several robustness tests; the results are reported in Table 6. Column 1 uses price instead of log of price as the dependent variable in Equation (5). Column 2 adopts a linear functional form. ${ }^{42}$ Column 3 is based on a semi-log specification. All results are consistent with our main findings using a log-linear specification.

Another robustness test includes competition as a control variable to estimate the curvature equation. In addition to examining how competition affects price curvature, this specification allows us to

\footnotetext{
42 We also run a regression of prices on hours and hours squared, and their interactions with competition measure (hour*competition and hour squared*competition). Because these two interaction terms are highly correlated in the data (the correlation is bigger than 0.9), both parameters in front of the interaction terms are small and insignificant.
} 
identify the impact of competition on the overall price levels. The results are reported in column 4 of Table 6. Consistent with our main findings, we find that increased competition is associated with a decrease in parking prices. Moreover, we find that short-term parking prices are proportionally affected more by competition than long-term prices. Note that in order to identify the effect of competition on price, we could not include garage specific fixed effects for the estimation reported in column 4. Instead, we add all the control variables used in Equation (1), such as land value and the census tract fixed effects. ${ }^{43}$

\section{d. Unobserved Heterogeneity and Price Curvature}

Our last robustness test considers the relationship between competition and price curvature as specified in Equation (4). In addition to controlling for competition in Equation (4), we also allow the other explanatory variables (i.e., those that are used in Equation (1)) to affect price curvature. This test attempts to examine whether our main results regarding price curvature are robust after controlling for other observed market-level characteristics and the census tract fixed effects. The inclusion of the census tract fixed effects may be useful, as it helps to control for unobserved market level heterogeneity that might be correlated with competition, and may also differentially affect prices of short- and long-term parking (thus correlated with the curvature of a price schedule).

The existence of unobserved heterogeneity at the market level might potentially confound our estimation of the relationship between competition and price curvature. One example of such unobserved

\footnotetext{
${ }^{43}$ We also conduct an analysis allowing for nonlinearity in the impact of competition on price curvature. In this case, we use different thresholds to define short- and long-term parking (such as 6-hour, or 7-hour), and we interact competition with dummies for short- and long-term parking. We consistently find that the proportional drop in prices of short-term parking is significantly larger than that in prices of long-term parking. Using three dummies (short-, mid- and long-term parking) has delivered similar results.
} 
heterogeneity is close proximity to a tourist attraction (e.g., a theater). High tourist traffic might attract more parking companies to enter a market. However, due to the specific nature of the demand of tourists, who usually visit an attraction for only a couple of hours, demand is higher for short-term parking relative to long-term parking, leading to higher relative prices of short-term parking. Therefore, such unobserved heterogeneity will be correlated with a greater degree of curvature in the price schedule (i.e., a smaller curvature parameter). Ignoring such unobserved heterogeneity would cause a negative bias in the estimation of the competition effect on price curvature in this case. Note that controlling for such unobserved heterogeneity would only reinforce our results about the relationship between competition and price curvature. Another example relates to the street parking availability. Street parking, especially meter parking, is often used for short-term parking. ${ }^{44}$ As a result, the availability of street parking could have a more negative impact on prices of short-term parking than long-term parking (increasing the curvature parameter). If competition is positively associated with the availability of street parking, this could lead to an upward bias in the estimation of the competition effect on price curvature. ${ }^{45}$

Our alternative specification for the curvature parameter $\gamma$ in Equation (4) leads to an alternative specification for Equation (5). Column 5 of Table 6 reports the estimation results, which are consistent with our main findings. 46

Note that the Table 6 estimation uses a radius of 0.5 miles from a center garage to define a market. Using 0.3-mile radius and price

\footnotetext{
${ }^{44}$ There are often limits to the number of hours that one can use for meter parking.

${ }^{45}$ However, we are not aware of any evidence suggesting that street parking is more available in areas with a higher level of competition.

${ }^{46}$ We only report the coefficients of our primary interest. The full results are available upon request.
} 
information up to 24 hours have delivered similar results, which are not reported in the interest of paper length.

\section{Discussions}

In order to conclude whether competition enhances or diminishes price discrimination in the parking garage industry, we first relate price discrimination to price-cost margin, and claim a larger degree of price discrimination exists if the variance of the price-cost margin increases. We then explain how to draw a conclusion regarding competition and price discrimination via empirical analysis of the relationship between competition and price curvature.

Our empirical analysis indicates that parking prices decrease with increased competition. Moreover, prices of short-term parking drop proportionally more than those of long-term parking. Figure 2 provides a simple illustration of how prices of different durations respond to an increase in competition. We find, based on a set of assumptions about the marginal costs of each hour of parking, enhanced competition leads to less price discrimination in the parking garage industry. ${ }^{47}$

We begin our discussion by assuming the marginal costs of each additional hour's parking are constant for a given garage. This assumption is valid because, when a parking garage is subject to capacity constraint, the tradeoff for selling each additional hour of parking is to forgo the spot for a potential 1-hour customer. ${ }^{48}$ Given this assumption,

\footnotetext{
${ }^{47}$ In the discussion below, one implicit assumption used is that costs do not change with the number of competitors in a market.

${ }^{48}$ We acknowledge that the costs of parking may be more complicated as there are often attendants who perform valet parking in garages in Manhattan. To take this into consideration, we decompose the costs into two parts: the first part refers to the forgone parking spot and the second relates to the labor costs of parking. The marginal costs (for per hour parking) might be lower for high duration parking, as labor costs could be spread over more hours. However, our findings regarding variance in the price-cost margin are robust as long as the labor costs per car are relatively small, which is likely to be the case given that the average hourly salary for a parking attendant is less than $\$ 7$ (based on reports from the Bureau of Labor Statistics, 2007).
} 
our empirical findings indicate that as competition increases, the pricecost margin decreases more for parking of short duration than for long duration. This leads to less dispersion in price-cost margin, and less price discrimination.

The above discussion is based on a scenario where a garage is likely to reach capacity. We complement our discussion by examining another scenario in which the capacity constraint is not binding. ${ }^{49}$ In this case, it is likely that the marginal costs of each additional hour's parking are zero. Interestingly, we arrive at the same conclusion in both scenarios because, in both cases, per-hour price differences reflect differences in price-cost margins. A larger drop in the low-end price reduces the difference in the per-hour price (and in the price-cost margin) across different parking durations, leading to less variation in the price-cost margin.

\subsection{A Search Explanation}

We find that low-end prices respond more to competition than highend prices in the parking garage industry. One explanation for our findings is that customers of short- and long-term parking have different search behaviors. Long-term parking customers are more likely to be informed consumers compared to their short-term parking counterparts, because long-term customers, such as commuters who park for work, are more likely to be repetitive users. These customers are more familiar with the area and more likely to be informed about the price distribution from friends and colleagues. Additionally, the incentive for long-term

\footnotetext{
${ }^{49}$ We also acknowledge the possibility that garages might switch back and forth between full and below capacity during the course of a day, which will complicate our analysis. However based on some anecdotal evidence, it is likely that most garages do not reach full capacity in Manhattan. For example, according to the 2006 North America central business districts parking rate survey conducted by the Colliers International, the availability of parking in Downtown and Midtown Manhattan New York City was considered to be fair. Parking garages are $60-80 \%$ full during weekends and special events.
} 
customers to price shop is greater because the gain from searching could be magnified by repeat consumption. In contrast, the benefit from searching for one-time short-term users may not cover the cost of driving around to find the lowest priced garage.

When more garages open in an area, it becomes less costly to canvass a number of garages due to shortened travel distance between garages. The lowered search costs may increase the search intensity of short-term customers, and lead to an increase in the fraction of informed customers. Long-term customers also increase their search intensity. However, relatively fewer long-term customers would change their search behaviors and become newly informed about the price distribution, because most of them may have already engaged in searching prior to an increase in competition. A more significant increase in informed customers of short-term parking leads to a larger drop in equilibrium prices. In summary, short-term prices are more responsive to competition than long-term prices, because search intensity of short-term customers responds more readily to changes in competition than that of long-term customers.

\subsection{Additional Evidence}

In order to support our hypothesis that short- and long-term customers differ in search intensities, we examine degrees of price dispersion of various parking durations using the coefficient of variation (CV), a commonly used measure for relative price dispersion. If people search less for short-term parking than for long-term parking, then we should expect larger price dispersion for short-term parking than for long-term parking. ${ }^{50}$

\footnotetext{
${ }^{50}$ Sorensen (2000) shows that prices for repeatedly purchased prescriptions exhibit significant reduction in price dispersion. Dahlby and West (1986) find that insurance premiums are least dispersed in driver classes for which a search is most likely
} 
We first estimate the CV of price dispersion by parking duration and market, with a market being defined as a radius of 0.5 miles from a center garage. ${ }^{51} \mathrm{We}$ then calculate the average $\mathrm{CV}$ across markets for each parking duration. ${ }^{52}$ Figure 3 shows the CV for up to 12 hours. The $\mathrm{CV}$ is relatively small for 1-hour and 2-hour parking, but at the 3-hour parking mark, it declines gradually as the parking duration increases. Although the relationship is not strictly monotonic, the price dispersion does show a decreasing trend for parking lasting longer than 3 hours.

We also conduct a regression of the $\mathrm{CV}$ on the corresponding parking durations and find a significantly negative relationship. We further examine whether the $\mathrm{CV}$ is significantly lower for long parking durations. To this end, we define long parking durations as parking duration longer than a certain threshold. We utilize several thresholds (i.e., any number between 3 and 7), and none of the tests reject the hypothesis that long-term parking has a smaller CV than short-term parking. Each of these observations suggests that long-term customers search more intensely than short-term customers.

Our search explanation is based on the heterogeneity in search behaviors across different types of consumers. Based on our theory, competition should have a smaller impact on price curvature in markets where the majority of the customers are informed of price distributions than in markets with an even mixture of informed and uninformed customers. In order to provide additional evidence for our search explanation, we focus our analysis on areas that are likely to have a large proportion of informed customers, such as residential areas. Residential

\footnotetext{
to occur.

${ }^{51}$ We have also used the census tract to define a market, and find similar results.

${ }^{52}$ We calculate both a simple average and a weighted average using the number of parking garages in each market as the weights. The results are similar, so we only report the results for a simple average.
} 
areas may have a higher percentage of informed customers than commercial areas because there are fewer one-time visitors to residential than commercial areas.

We rely on a zoning variable (whether a garage belongs to a commercial, residential or manufacturing zone) in order to identify markets that are primarily residential. We first examine zoning distribution by neighborhood. Most neighborhoods are comprised of a relatively even mixture of commercial and residential zones. One exception is the Upper East Side neighborhood, which has a much larger ratio of garages in residential zones than in commercial zones (73\% vs. 27\%). The other exception is the Midtown Upper East Side neighborhood, which has a much larger ratio of garages in commercial zones (72\% vs. 27\%) than in residential zones. We consider the Upper East Side to have a higher proportion of informed customers than other neighborhoods, and the Midtown Upper East Side to have a larger proportion of uninformed customers. We examine how competition affects price curvatures for garages located in these two neighborhoods. The results are reported in columns 1 and 2 of Table 7. As expected, we find a small and insignificant impact of competition on price curvature in the Upper East Side, but a large and significant impact in the Midtown Upper East Side.

We also calculate the residential ratio using the fraction of garages that belong to a residential zone in a market as a measure for whether a market is relatively residential. ${ }^{53}$ We study markets with residential ratios at the top $20^{\text {th }}$ percentile (with residential ratio higher than 0.57 ), and markets at the bottom $20^{\text {th }}$ percentile (with residential ratio lower than 0.13$).{ }^{54}$ Markets with larger residential ratios are considered to have

\footnotetext{
${ }^{53}$ In this analysis, we use 0.5 miles as the radius to define a market.

${ }^{54}$ Using some alternative thresholds, such as the top $30^{\text {th }}$ and bottom $30^{\text {th }}$ percentiles, has delivered similar results.
} 
a higher portion of informed customers, and we expect competition should have a less impact on price curvature in these markets. Column 3 of Table 7 reports the results for markets at the top $20^{\text {th }}$ percentile in residential ratio distribution. As expected, we find the impact of competition on price curvature is smaller than those found in our main results (reported in column 4 of Table 4), and statistically insignificant. Column 4 reports the results for markets at the bottom $20^{\text {th }}$ percentile. Compared to the results in column 3 , we see a much larger and significant effect of competition on price curvature. The above results provide additional support to our search explanation based on heterogeneous search behaviors across different types of customers.

\subsection{Comparison to Busse and Rysman (2005)}

We find that an increase in competition causes low-end prices to drop proportionally more than high-end prices in the parking garage industry. Our findings contradict those of Busse and Rysman (2005), as they find that increased competition is associated with a greater curvature, that is, prices of large ads respond more to competition than those of small ads in the Yellow Pages advertising industry. Several factors may have contributed to the disparity of results between these two studies. First, the parking garage industry sees a combination of second- and third-degree price discrimination, whereas the Yellow Pages advertising industry only exhibits second-degree price discrimination. Second, and more importantly, differences in search behaviors across consumer groups that may play an important role in the parking garage industry are not characteristic of the Yellow Pages advertising industry. Finally, Busse and Rysman (2005) cite network effects as one possible explanation for their results, but the parking garage industry does not exhibit network externality. 


\section{Conclusions}

This paper adds to the empirical literature on price discrimination and competition by examining the nonlinearity in hourly price schedules in the parking garage industry. We find that competition drives down price levels for parking. This result, together with our examination of the relationship between price curvature and competition, leads us to conclude that prices of short-term parking drop proportionately more than those of long-term parking as competition intensifies. As a result, competition is associated with a lower degree of price discrimination. We provide an explanation for our findings using differences in search behaviors between short- and long-term customers.

This paper also sheds light on an important limitation in previous theoretical literature on consumer search and equilibrium prices. Existing theories tend to downplay the importance of allowing for varying search costs given a change in market competition. However, search costs may be negatively related to market density, especially in cases where firm heterogeneity is largely geographical. In such cases, increased competition lowers search costs, encouraging less informed consumers to engage in more searches. If such a change in search costs is taken into account, it should be expected that, in addition to a decrease in uninformed consumers per firm due to an increase in the number of competitors, the segment of uninformed consumers would shrink with increased competition. This result would strengthen the business-stealing effect, inducing firms to attach more importance to the informed group. If this effect is large enough, it would dominate the surplusappropriation effect and lead to a reduction in the expected equilibrium price. 


\section{Appendix: An Example of Constructing Price Schedules Using}

\section{Appropriate Rates}

Suppose that a garage that operates from 6 a.m. to 12 a.m. and posts the following rates:

\begin{tabular}{|l|l|}
\hline Parking Duration & Rate \\
\hline 1 hour & 10 \\
\hline 2 hours & 15 \\
\hline 5 hours & 18 \\
\hline 10 hours & 22 \\
\hline Maximum rate & 25 \\
\hline Overnight rate & 30 \\
\hline $\begin{array}{l}\text { Early bird special (enter b/w 6 a.m. and 10 a.m., leave } \\
\text { before 6 p.m., max stay 8 hours) }\end{array}$ \\
\hline
\end{tabular}

The maximum rate only applies during the current day, which is before closing time. Once someone parks past closing time, the overnight rate applies until the duration reaches 24 hours. Suppose that a customer enters the garage at 8 a.m. The price schedule she faces looks like the following: 


\begin{tabular}{|l|l|l|l|}
\hline & Exiting time & Price & Explanation \\
\hline 1 hour & 9 a.m. & $\$ 10$ & 1 hour rate applies \\
\hline 2 hours & 10 a.m. & $\$ 12$ & Early bird special overrides 2 hour rate \\
\hline 3 hours & 11 a.m. & $\$ 12$ & Early bird special overrides 5 hour rate \\
\hline 4 hours & 12 p.m. & $\$ 12$ & Early bird special overrides 5 hour rate \\
\hline 5 hours & 1 p.m. & $\$ 12$ & Early bird special overrides 5 hour rate \\
\hline 6 hours & 2 p.m. & $\$ 12$ & Early bird special overrides 10 hour rate \\
\hline 7 hours & 3 p.m. & $\$ 12$ & Early bird special overrides 10 hour rate \\
\hline 8 hours & 4 p.m. & $\$ 12$ & Early bird special overrides 10 hour rate \\
\hline 9 hours & 5 p.m. & $\$ 22$ & 10 hour rate applies \\
\hline 10 hours & 6 p.m. & $\$ 22$ & 10 hour rate applies \\
\hline 11 hours & 7 p.m. & $\$ 25$ & Maximum rate applies \\
\hline 12 hours & 8 p.m. & $\$ 25$ & Maximum rate applies \\
\hline 13 hours & 9 p.m. & $\$ 25$ & Maximum rate applies \\
\hline 14 hours & 10 p.m. & $\$ 25$ & Maximum rate applies \\
\hline 15 hours & 11 p.m. & $\$ 25$ & Maximum rate applies \\
\hline 16 hours & 12 a.m. & $\$ 25$ & Maximum rate applies \\
\hline 17 hours & 1 a.m. & N/A & Garage closed \\
\hline 18 hours & 2 a.m. & N/A & Garage closed \\
\hline 19 hours & 3 a.m. & N/A & Garage closed \\
\hline 20 hours & 4 a.m. & N/A & Garage closed \\
\hline 21 hours & 5 a.m. & N/A & Garage closed \\
\hline 22 hours & 6 a.m. & $\$ 30$ & Overnight rate applies \\
\hline 23 hours & 7 a.m. & $\$ 30$ & Overnight rate applies \\
\hline 24 hours & 8 a.m. & $\$ 30$ & Overnight rate applies \\
\hline
\end{tabular}




\section{References}

Armstrong, Mark, and John Vickers. 2001. "Competitive Price Discrimination," RAND Journal of Economics, 32 (4): 579-605.

Baye, Michael, John Morgan, and Patrick Scholten. 2006. “Information, Search, and Price Dispersion,” Chapter 6 in Handbook in Economics and Information Systems, Volume 1 (T. Hendershott, Ed.), Amsterdam: Elsevier

Borenstein, S. 1989. "Hubs and High Fares: Dominance and Market Power in the U.S. Airline Industry," Rand Journal of Economics, 20 (3): 344-365

Borenstein, S. 1991. "Selling Costs and Switching Costs: Explain Retail Gasoline Margins," Rand Journal of Economics, 22 (3): 354-69.

Borenstein S. and Nancy Rose. 1994. "Competition and Price Dispersion in the U.S. Airline Industry,” Journal of Political Economy, 102 (4): 653-83.

Borzekowski, R., R. Thomadsen, and C. Taragin. 2009. “Competition and Price Discrimination in the Market for Mailing Lists,” Quantitative Marketing and Economics, 7 (2): 147-179.

Bresnahan, Timothy, and Peter Reiss. 1991. "Entry and Competition in Concentrated Markets," Journal of Political Economy, 99 (5): 977-1009.

Burdett, Kenneth, and Kenneth Judd. 1983. "Equilibrium Price Dispersion," Econometrica, 51 (4): 955-969.

Busse, Meghan, and Marc Rysman. 2005. "Competition and Price Discrimination in Yellow Pages Advertising," Rand Journal of Economics, 36 (2): 378-390.

Carlson, John, and R. Preston McAfee. 1983. "Discrete Equilibrium Price Dispersion," Journal of Political Economy, 91 (3): 480-493.

Clay, Karen, Ramayya Krishnan, and Eric Wolff 2001. "Prices and Price Dispersion on the Web: Evidence from the Online Book Industry," Journal of Industrial Economics, 49 (4): 521-540.

Clerides, Sofronis. 2004. " Price Discrimination with Differentiated Products: Definition and Identification," Economic Inquiry, 42(3): 402-412.

Cohen, Andrew. 2008. "Package Size and Price Discrimination in the Paper Towel Market," International Journal of Industrial Organization, 26, 502-516.

Colliers International, 2007. "North America CBD parking Rate Survey Highlights." 
Dahlby, Bev and Douglas West. 1986. "Price Dispersion in an Automobile Insurance Market," Journal of Political Economy, 94 (2): 418-438.

Dai, Mian, Qihong Liu and Konstantinos Serfes. 2012. "Is the Effect of Competition on Price Dispersion Non-Monotonic? Evidence from the U.S. Airline Industry," conditionally accepted, Review of Economics and Statistics.

Evans, William, Luke Froeb and Gregory Werden. 1993. "Endogeneity in the Concentration-Price Relationship: Causes, Consequences, and Cures,” Journal of Industrial Economics, 41 (4): 431-438.

Gerardi, K.S., and A.H. Shapiro. 2009. "Does Competition Reduce Price Dispersion? New Evidence from the Airline Industry," Journal of Political Economy, 117 (1): 1-37.

Heckman, James. 1979. "Sample Selection Bias as Specification Error," Econometrica, 47 (1): 153-161.

Janssen, M. and J. L. Moraga-González. 2004. "Strategic Pricing, Consumer Search and the Number of Firms,” Review of Economic Studies, 71 (4): 1089-1118.

Lach, S. and Moraga-González, J. L. 2012, “Heterogeneous Price Information and the Effect of Competition,” working paper, The Hebrew University.

Manuszak, Mark, and Charles Moul. 2008. "Prices and Endogenous Market Structure in Office Supply Superstores," Journal of Industrial Economics, 56 (1): 94-112.

Mazzeo, Michael. 2002a. "Competitive Outcomes in Product-Differentiated Oligopoly," Review of Economics and Statistics, 84 (4): 716-728.

Mazzeo, Michael. 2002b. "Product Choice and Oligopoly Market Structure," Rand Journal of Economics, 33 (2): 221-242.

Morgan, John, Henrik Orzen, and Martin Sefton. 2006. "An Experimental Study of Price Dispersion," Games and Economic Behavior, 54(1): 134-158.

Pratt, John, David Wise, and Richard Zeckhauser. 1979. "Price Differences in Almost

Competitive Market," Quarterly Journal of Economics, 93 (2): 189-211.

Reinganum, Jennifer. 1979. "A Simple Model of Equilibrium Price Dispersions," Journal of Political Economy, 87 (4): 851-858.

Rochet, J. C., and L. Stole. 2002. “Nonlinear Pricing with Random Participation,” Review of Economic Studies, 69 (1): 277-311.

Rosenthal, R.W. 1980. “A Model in Which an Increase in the Number of Sellers Leads to a Higher Price,” Econometrica, 48 (6): 1575-1580. 
Salop, Steven, and Joseph Stiglitz. 1977. "Bargains and Ripoffs: A Model of Monopolistically Competitive Prices," Review of Economic Studies, 44 (3): 493-510.

Satterthwaite, M. 1979. "Consumer Information, Equilibrium Industry Price, and the Number of Sellers." Bell Journal of Economics, 10 (2): 483-502.

Schulz, N., and Stahl. K. 1996. "Do Consumers Search for the Higher Price? Oligopoly Equilibrium and Monopoly Optimum in Differentiated-Products Markets." Rand Journal of Economics 27 (3): 542-562.

Seim, Katja. 2006. "An Empirical Model of Firm Entry with Endogenous Product-Type Choices," Rand Journal of Economics, 37 (3): 619-640.

Seim, Katja, and V. Brian Viard. 2011. "The Effect of Market Structure on Cellular Technology Adoption and Pricing," American Economic Journal: Microeconomics, 3 (2): 221-51.

Schmalensee, Richard. 1988. "Inter-Industry Studies of Structure and Performance," Handbook of Industrial Organization, Volume II, Elsevier Science Publishing Co., New York.

Sorensen, Alan. 2000. "Equilibrium Price Dispersion in Retail Markets for Prescription Drugs," Journal of Political Economy, 108 (4): 833-850.

Stahl, D. O. 1989. “Oligopolistic Pricing with Sequential Consumer Search,” American Economic Review, 79 (4): 700-712.

Stahl, D. O. 1996. “Oligopolistic Pricing with Heterogeneous Consumer Search,” International Journal of Industrial Organization, 14 (2): 243-26.

Stavins, J., 2001. "Price Discrimination in the Airline Market: the Effect of Market Concentration,” Review of Economics and Statistics, 83 (1): 200-202.

Stigler, George. 1961. "The Economics of Information," Journal of Political Economy, 69 (3): 213-225.

Stiglitz, J. 1987. "Competition and the Number of Firms in a Market: Are Duopolists More Competitive Than Atomistic Markets?" Journal of Political Economy, 95 (5): 1041-1061

Stole, L. 1995. "Nonlinear Pricing and Oligopoly,” Journal of Economics and Management Science, 4(4): 529-562.

Tirole, Jean. 1988. The Theory of Industrial Organization, MIT Press, Cambridge, MA. Varian, Hal R. 1980. "A Model of Sales," American Economic Review, 70 (3): 651-659. 
Verboven, F. 1999. "Product Line Rivalry and Market Segmentation -with an Application to Automobile Optional Engine Pricing," Journal of Industrial Economics, 47 (4): 399-425.

Weiss, Leonard. 1989. Concentration and Prices, MIT Press, Cambridge, MA.

Wilde, Louis, and Alan Schwartz. 1979. "Equilibrium Comparison Shopping," Review of Economic Studies, 46 (144): 543-553.

Zhu, Ting, Vishal Singh, and Mark Manuszak. 2009. "Market Structure and Competition in the Retail Discount Industry," Journal of Marketing Research, 46 (4): 453-466. 
Figure 1: A Map of the Garage Locations

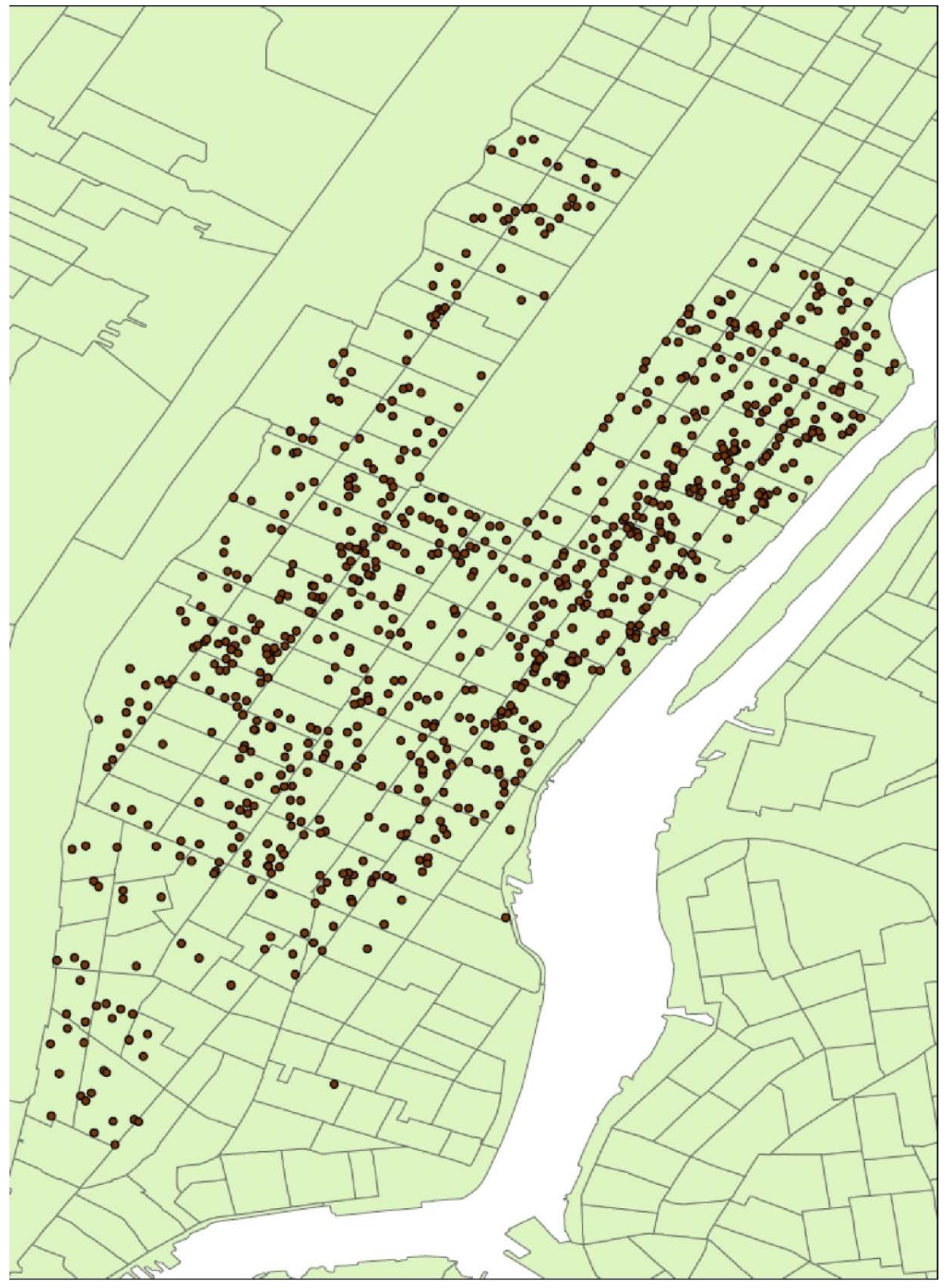


Figure 2: Price Reduction Not Uniform along Parking Hours

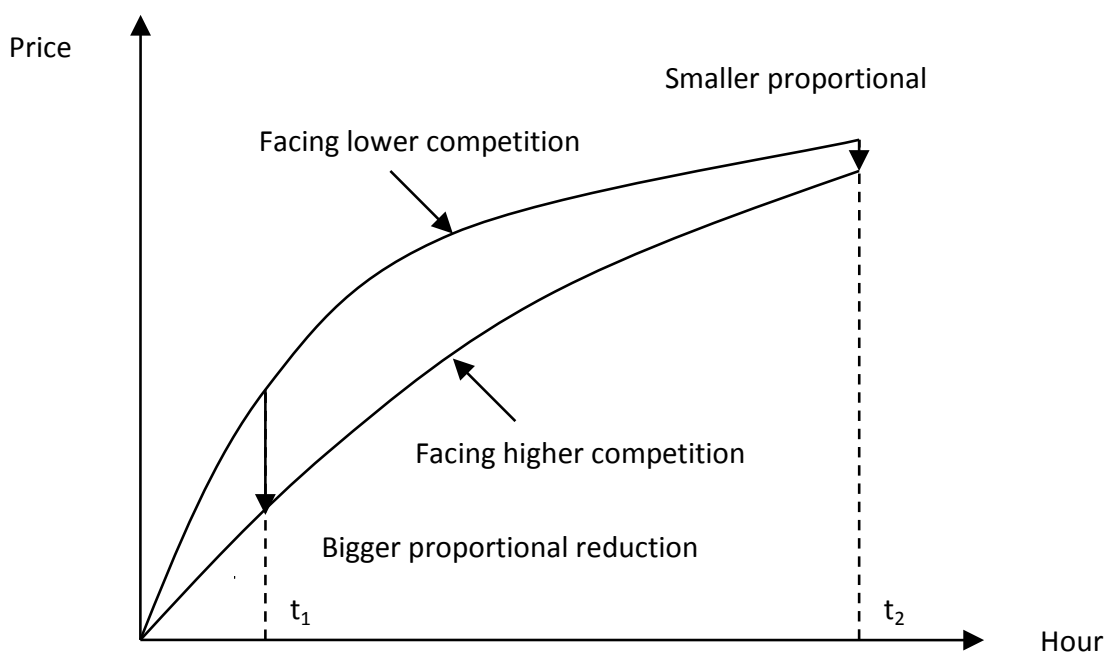

Figure 3: Coefficient of Variation along Parking Hours

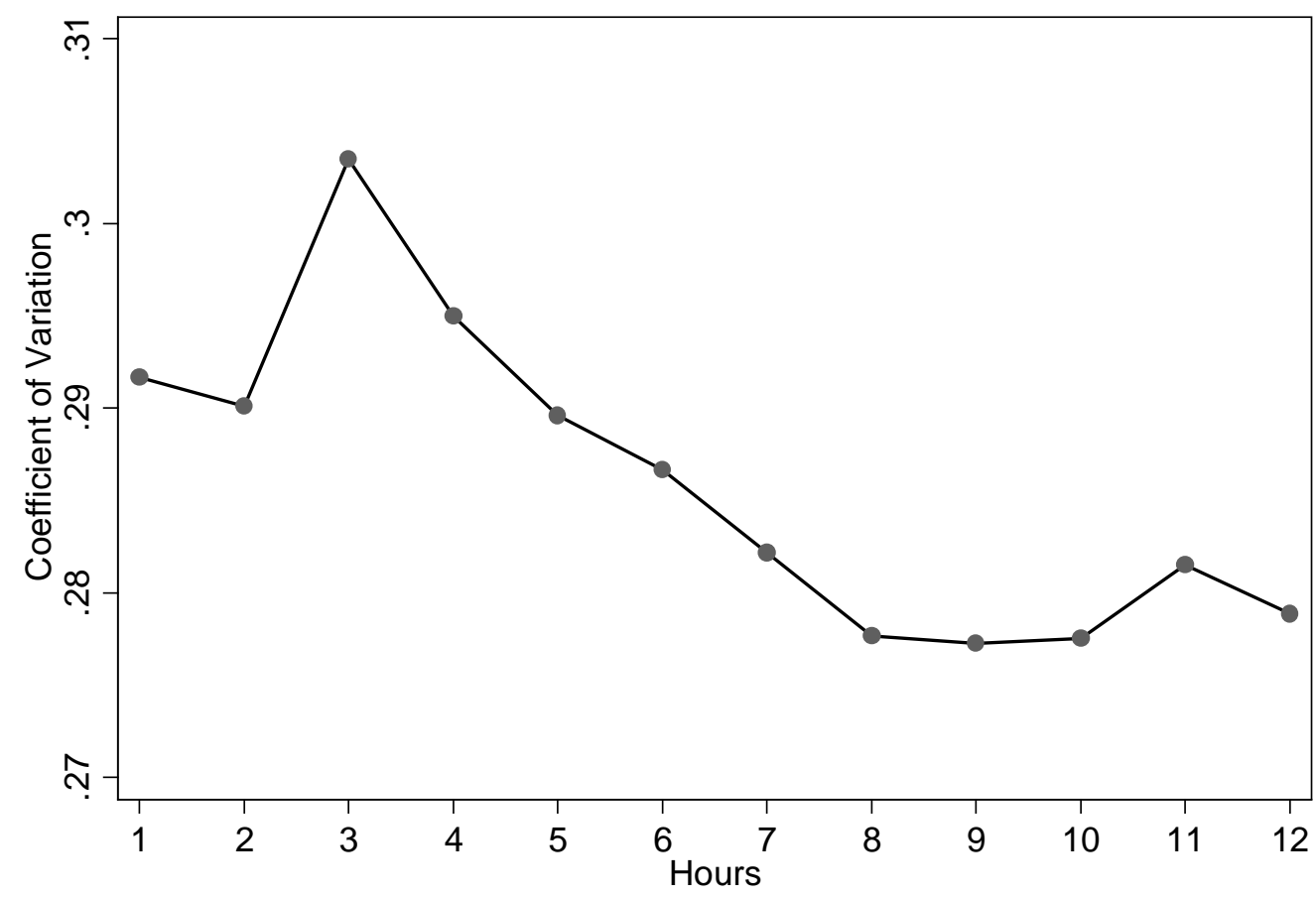

Note: Entering time is $12 \mathrm{pm}$ 
Table 1A: Summary Statistics of Pricing

\begin{tabular}{lrr}
\hline \hline & Median & S.D. \\
\hline Prices & & \\
1 hour & 12.67 & 4.4 \\
2 hours & 16.05 & 5.65 \\
3 hours & 20.27 & 7.09 \\
4 hours & 21.12 & 7.3 \\
5 hours & 21.14 & 7.56 \\
6 hours & 21.15 & 7.53 \\
7 hours & 21.96 & 7.47 \\
8 hours & 21.96 & 7.44 \\
9 hours & 22.81 & 7.21 \\
10 hours & 22.81 & 7.23 \\
11 hours & 25.34 & 8.21 \\
12 hours & 25.34 & 8.15 \\
Operating Length (hours) & 24 & 3.61 \\
Number of Posted Rates & 5 & 1.44
\end{tabular}

Competition and Other Measures within 0.3 Miles:

$\begin{array}{lll}\mathrm{HHI} \text { by Ownership } & 0.124 & 0.082\end{array}$

$\begin{array}{lrl}\mathrm{HHI} \text { by Capacity } & 0.160 & 0.095\end{array}$

Number of Competing Companies $\quad 16 \quad 6.805$

Number of Competing Parking Garages $\quad 3312.025$

$\begin{array}{lll}\text { Four Firm Concentration Ratio } & 0.581 & 0.125\end{array}$

Proportion of Garages Owned by the Center Garage's Company $\quad 0.097 \quad 0.138$

Competition and Other Measures within 0.5 Miles:

HHI by Ownership $\quad 0.105 \quad 0.038$

$\mathrm{HHI}$ by Capacity $\quad \begin{array}{ll}0.133 & 0.048\end{array}$

Number of Competing Companies $\quad 3011.011$

Number of Competing Parking Garages $\quad 8323.760$

$\begin{array}{lll}\text { Four Firm Concentration Ratio } & 0.550 & 0.079\end{array}$

Proportion of Garages Owned by the Center Garage's Company $\quad 0.071 \quad 0.105$ 
Table 1B: Summary Statistics of the Areas Where the Garages are Located

\begin{tabular}{lcc}
\hline \hline Variable & Mean & S. D. \\
\hline Commercial Zone Dummy & 0.593 & 0.492 \\
Residential Zone Dummy & 0.339 & 0.474 \\
Manufacturing Zone Dummy & 0.068 & 0.252 \\
Land Value (in \$1000s per sq. ft.) & 0.281 & 0.306 \\
Median Income of Census Tracts (in \$1000s) & 72.328 & 26.763 \\
Total Population (in 1000s) & 6.043 & 3.799 \\
Zoning Density (ranges from 1 to 9) & 3.958 & 2.745 \\
\hline
\end{tabular}

Table 2: Regression of the Parking Price on the Competition Measure

\begin{tabular}{lcccc}
\hline \hline & $(1)$ & $(2)$ & $(3)$ & $(4)$ \\
& $0.3 \mathrm{M}$ & $0.5 \mathrm{M}$ & $0.3 \mathrm{M}$ & $0.5 \mathrm{M}$ \\
\hline - HHI & -0.414 & -0.448 & $-0.954^{* * *}$ & $-2.874^{* * *}$ \\
& $(0.252)$ & $(0.405)$ & $(0.309)$ & $(1.030)$ \\
Land Value & $0.146^{* * *}$ & $0.146^{* * *}$ & 0.020 & 0.016 \\
& $(0.040)$ & $(0.040)$ & $(0.042)$ & $(0.042)$ \\
Median income & $0.004^{* * *}$ & $0.004^{* * *}$ & & \\
& $(0.000)$ & $(0.000)$ & & \\
Total Population & $-0.028^{* * *}$ & $-0.029^{* * *}$ & & \\
& $(0.004)$ & $(0.004)$ & & \\
Prop_Owncomp & $0.288^{* *}$ & $0.252^{* *}$ & $0.526^{* * *}$ & $0.195^{*}$ \\
& $(0.133)$ & $(0.121)$ & $(0.147)$ & $(0.110)$ \\
Manufacturing District & -0.049 & -0.044 & $0.162^{* *}$ & $0.144^{* *}$ \\
& $(0.060)$ & $(0.060)$ & $(0.065)$ & $(0.066)$ \\
Residential District & $-0.080^{*}$ & -0.071 & -0.013 & -0.018 \\
& $(0.048)$ & $(0.048)$ & $(0.050)$ & $(0.051)$ \\
Zoning Density & 0.009 & 0.008 & $0.027^{* * *}$ & $0.023^{* *}$ \\
& $(0.008)$ & $(0.008)$ & $(0.009)$ & $(0.009)$ \\
Zoning Density*Resid. Dist & -0.006 & -0.006 & $-0.023^{* *}$ & $-0.020^{*}$ \\
& $(0.010)$ & $(0.010)$ & $(0.011)$ & $(0.011)$ \\
Constant & $2.277^{* * *}$ & $2.291^{* * *}$ & $2.266^{* * *}$ & $2.116^{* * *}$ \\
& $(0.075)$ & $(0.075)$ & $(0.060)$ & $(0.111)$ \\
\hline Census Tract Fixed Effects & No & No & Yes & Yes \\
Number of Garages & 602 & 602 & 602 & 602 \\
R-squared-adjusted & 0.316 & 0.316 & 0.562 & 0.563 \\
\hline Note: Robust standard errors are in parentheses. *** $\mathrm{p}<0.01, * * \mathrm{p}<0.05, * \mathrm{p}<0.1$. & \\
& & & &
\end{tabular}


Table 3: Summary of the Estimated Curvature Coefficients

\begin{tabular}{|c|c|c|}
\hline & Entering at 12 p.m. & Entering at 8 a.m. \\
\hline Mean & 0.246 & 0.171 \\
\hline Standard Deviation & 0.114 & 0.121 \\
\hline Observation & 797 & 797 \\
\hline Minimum & 0 & 0 \\
\hline Maximum & 0.978 & 0.952 \\
\hline \% Significantly Differ from 1 & $99 \%$ & $99 \%$ \\
\hline \multicolumn{3}{|l|}{ Percentiles } \\
\hline $5 \%$ & 0.085 & 0 \\
\hline $25 \%$ & 0.180 & 0.085 \\
\hline $50 \%$ & 0.237 & 0.166 \\
\hline $75 \%$ & 0.302 & 0.243 \\
\hline $90 \%$ & 0.372 & 0.324 \\
\hline
\end{tabular}

Note: We include all the garages in the original data when calculating the curvature coefficients. Narrowing the sample to 602 garages in the final sample has delivered very similar results.

Table 4: Price Curvature and Competition

\begin{tabular}{lcccc}
\hline \hline & $(1)$ & $(2)$ & $(3)$ & $(4)$ \\
& $0.3 \mathrm{M}$ & $0.5 \mathrm{M}$ & $0.3 \mathrm{M}$ & $0.5 \mathrm{M}$ \\
\hline - HHI * $\ln ($ hour) & -0.084 & 0.117 & $0.141^{* *}$ & $0.691^{* * *}$ \\
& $(0.069)$ & $(0.157)$ & $(0.058)$ & $(0.110)$ \\
$\ln ($ hour) & $0.236^{* * *}$ & $0.261^{* * *}$ & $0.267^{* * *}$ & $0.324^{* * *}$ \\
& $(0.011)$ & $(0.018)$ & $(0.010)$ & $(0.013)$ \\
& & & & \\
Covered Hours & $1-12$ & $1-12$ & $1-12$ & $1-12$ \\
Garage Fixed Effects & $\mathrm{No}$ & $\mathrm{No}$ & Yes & Yes \\
Number of Garages & 602 & 602 & 602 & 602 \\
Number of Observation & 7104 & 7104 & 7104 & 7104 \\
R-squared-adjusted & 0.597 & 0.597 & 0.879 & 0.879 \\
\hline
\end{tabular}


Table 5: Robustness Tests on Competition Measures and Sample Selection
(1)
(2)
(3)
(4)

Panel A: Price Equation

$\begin{array}{lcccc}\text { Competition } & -1.426 * * * & -0.241 * * & -0.211^{* *} & -3.299 * * * \\ & (0.509) & (0.111) & (0.093) & (0.806) \\ \text { Prop_Owncomp } & 0.724 * * * & 0.206^{*} & 0.213^{*} & 1.226^{* * *} \\ & (0.216) & (0.110) & (0.110) & (0.276) \\ \text { Census Tract Fixed Effects } & \text { Yes } & \text { Yes } & \text { Yes } & \text { Yes }\end{array}$

Panel B: Curvature Equation

\begin{tabular}{lcccc} 
Competition * $\ln$ (hour) & $\begin{array}{c}0.537 * * * \\
\end{array}$ & $0.035^{* * *}$ & $0.019^{*}$ & $0.680^{* * *}$ \\
& $(0.083)$ & $(0.013)$ & $(0.010)$ & $(0.111)$ \\
$\ln$ (hour) & $\left(0.320^{* * *}\right.$ & $0.129 * * *$ & $0.181^{* * *}$ & $0.322^{* * *}$ \\
& & $(0.043)$ & $(0.036)$ & $(0.014)$ \\
Covered Hours & $1-12$ & $1-12$ & $1-12$ & $1-12$ \\
Garage Fixed Effects & Yes & Yes & Yes & Yes \\
Number of Garages & 602 & 602 & 602 & 533 \\
Number of Observations & 7104 & 7104 & 7104 & 6303 \\
\hline
\end{tabular}

Note: The first three columns use alternative competition measures. Column 1 uses the HHI (negative) calculated as the summation of the squared fraction of parking capacities owned by each company. Column 2 uses the log of the number of parking companies. Column 3 uses the log of the number of parking garages. Column 4 uses an alternative sample based on a more restrictive sample selection criterion. 
Table 6: Robustness Tests on Functional Forms

\begin{tabular}{lccccc}
\hline \hline & $(1)$ & $(2)$ & $(3)$ & $(4)$ & $(5)$ \\
& Price & Price & $\log ($ Price $)$ & $\log ($ Price $)$ & Log(Price) \\
\hline - HHI * $\ln ($ hour) & $5.869^{* * *}$ & & & $0.694^{* * *}$ & $0.591^{* * *}$ \\
& $(2.211)$ & & & $(0.111)$ & $(0.133)$ \\
$\ln$ (hour) & $5.401^{* * *}$ & & & $0.324^{* * *}$ & $0.308^{* * *}$ \\
& $(0.261)$ & & & $(0.014)$ & $(0.028)$ \\
& & & & \\
- HHI * hour & & $1.827^{* * *}$ & $0.162^{* * *}$ & & \\
& & $(0.462)$ & $(0.023)$ & & \\
hour & & $1.121^{* * *}$ & $0.064^{* * *}$ & & \\
& $(0.056)$ & $(0.003)$ & & \\
- HHI & & & & $-4.123^{* * *}$ & \\
& & & & $(0.899)$ & \\
Covered Hours & $1-12$ & $1-12$ & $1-12$ & $1-12$ & $1-12$ \\
Garage Fixed Effects & $\mathrm{Y}$ & $\mathrm{Y}$ & $\mathrm{Y}$ & $\mathrm{N}$ & $\mathrm{Y}$ \\
Number of Garages & 602 & 602 & 602 & 602 & 602 \\
Number of Observations & 7104 & 7104 & 7104 & 7104 & 7104 \\
\hline
\end{tabular}

Table 7: Competition and Curvature: Primarily Residential vs Primarily Commercial Areas

\begin{tabular}{lcccc}
\hline & $(1)$ & $(2)$ & $(3)$ & $(4)$ \\
& Upper East & Mid Upper East & Rratio $>=0.57$ & Rratio $<=0.13$ \\
\hline$-\mathrm{HHI} * \ln$ (hour) & 0.093 & $0.907^{* *}$ & 0.231 & $0.742^{* * *}$ \\
& $(0.389)$ & $(0.457)$ & $(0.449)$ & $(0.248)$ \\
$\ln$ (hour) & $0.248^{* * *}$ & $0.336^{* * *}$ & $0.318^{* * *}$ & $0.322^{* * *}$ \\
& $(0.038)$ & $(0.054)$ & $(0.037)$ & $(0.034)$ \\
Covered Hours & & & & \\
Garage Fixed Effects & $1-12$ & $1-12$ & $1-12$ & $1-12$ \\
Number of Garages & $\mathrm{Y}$ & $\mathrm{Y}$ & $\mathrm{Y}$ & $\mathrm{Y}$ \\
Number of Observations & 660 & 97 & 123 & 115 \\
& & 1159 & 1476 & 1305 \\
\hline
\end{tabular}

